\title{
LETTERS
}

\section{Supporting Bill S-206 protects Canadian children from violence}

Violence is a major determinant of many adverse health outcomes in Canada and worldwide, and it is unacceptable in all forms. The evidence base on effective interventions to prevent violence is now robust. ${ }^{1}$ Experience of and exposure to violence in childhood is a prominent adverse childhood experience and is linked to numerous adverse health outcomes immediately and into adulthood. ${ }^{2}$ For these reasons, Canadian Senate Bill S-206, which would see the exemption for parental and loco parentis use of physical force in Section 43 of the Criminal Code of Canada removed, is important. ${ }^{3}$ It is shameful that the criminal code still enables violence against children; at the present time, this is the only type of family violence that is sanctioned. Bill S-206 represents an opportunity to correct this through repeal of Section $43 .{ }^{4}$

Violence is a lifelong problem that many physicians witness routinely. Although treat- ment for and detection of violence is important, prevention is of utmost importance. Prevention must begin in childhood, by removing exposures to parenting violence. ${ }^{5}$ We recognize that removing the exemption for child-rearing violence by passing Bill S-206 is only a first step; however, it is a necessary one. Canadian parents must be shown that violence is not a part of parenting, and education for parents on more positive child-rearing techniques should be supported simultaneously. Until this is done, violence experienced in childhood will only continue to propagate the cycles of violence plaguing our communities.

We urge physicians to write their Senator to advocate support for Senate Bill S-206 and to continue clinical education that supports parents and caregivers in nonviolent child-rearing.

\section{Lisa K. Freeman MD MPH}

Assistant Clinical Professor, Department of Family Medicine, Faculty of Medicine and Dentistry, University of Alberta, Edmonton, Alta.

\section{Thomas Piggott BScH MD}

Resident Physician, Department of Health Research Methods, Evidence, and Impact, McMaster University, Hamilton, Ont.

Cite as: CMAJ 2017 September 5;189:E1119. doi: 10.1503/cmaj.733291

\section{References}

1. Krug EG, Dhalberg LL, Mercy JA, et al., editors. World report on violence and health. Geneva: World Health Organization; 2002.

2. Felitti VJ, Anda RF, Nordenberg D, et al. Relationship of childhood abuse and household dysfunction to many of the leading causes of death in adults: the Adverse Childhood Experiences (ACE) study. Am J Prev Med 1998;14:245-58.

3. Bill S-206: An Act to amend the Criminal Code (protection of children against standard childrearing violence). 42nd Parliament, 1st sess.; 2015. Available: https://openparliament.ca/ bills/42-1/S-206/ (accessed 2017 June 2).

4. Fletcher J. Positive parenting, not physical punishment. CMAJ 2012;184:1339.

5. INSPIRE: seven strategies for ending violence against children. Geneva: World Health Organization; 2016.

Competing interests: None declared. 